\title{
Shape-shifting connections, relationships and Pacific education in the uncharted waters of a global pandemic
}

\author{
Cherie Chu-Fuluifaga
}

\section{Victoria University of Wellington}

The importance of maintaining connections and relationships across tertiary education for students is discussed as a way of examining the nature of Pacific education in challenging times, particularly in terms of fractured face-to-face learning. Universities have been thrust into an unpredictable time of remote/distance/online learning in a short period of time. The process has been unsettling and challenging for people across the world. As Pacific students and staff experience the unchartered waters of Covid-19 and global disturbances, they are searching out ways to build purposeful connections, shape-shifting and ways to maintain communities of academic togetherness while harnessing the tools of their knowledge trajectories in research. This article will focus on four key principles: valuing personal and academic connections beyond the textbook; discovering heart-warming methods of connection; and connecting for growth and wellbeing.

Keywords: Pacific, Pacific education, shape-shifting, Covid-19, relationships

\section{Introduction}

As a university lecturer I operate in a constant reflective mode which is integral to developing courses and teaching that enables student learning and transformation. My self-defined vision as an educator is relative to the lives of many of my Pacific students. They want to do well at university. I want them to do well. They want to change narratives about the dialogue of being called failures, the production of low achievement rates in schooling, and most of all they want change for their communities. I want to change systems for my students so that they can achieve success on their own terms. Western paradigms in traditional research and academia determine the lines of objectivity and have expected researchers to remain as outsider researchers. But for many years, a new wave of Pacific approaches have challenged the status quo of research, presenting creative and culturally relevant forms of engaging in examining a topic or research concept. Many of us who are of Pacific heritage are embedded in the process of documenting our own processes and narratives which then become knowledge bases for transformation. Based on this premise, I have taken an explorative autoethnographic approach to reflecting on the challenges of the Covid-19 pandemic and its impact on Pacific students in my class.

\section{My shape-shifter positioning}

I see myself as a shape-shifter. I am Tahitian and Chinese through my bloodline. I have always moved and entered spaces that are of challenge and that are different to my own identity. But that makes me who I am. I shape-shift. The notion of shape-shifting emerges from various cultural stories and mythologies across the world. To shape-shift is to change 
form or shape through magical methods. Such narratives relate to animals and humans changing into another form of an animal or human to hunt, fight, protect, love, hate, and for other types of behaviour. I shape-shift to move with other peoples' contexts and needs. By doing this I ensure that my students achieve to their potential. Within this article, I present a shape-shifting ethnographic approach to teaching and learning with my university students in the most challenging and critical time of lockdowns of the Covid-19 pandemic. As I reflected on the course, the concept of shape-shifting required me to carry my passionate face-to-face teaching into the online environment. I am deliberate as an educator, and I teach with purpose because my classes are about making changes for Pacific peoples. My energy expressed in my teaching had to move with the lockdown. I knew that I had to create an online learning village synonymous to my in-person teaching style and approach.

\section{Success is more than a grade}

What is success for Pacific people in education? Pacific scholars have tried to address this issue of success for Pacific in all forms of education (Perrot, 2015). While there are signs that Pacific achievement is trending up and has made incremental improvements comparable to other groups, Pacific students are still behind statistically (Southwick et al., 2017). Research has shown that achievement for Pacific in education should be focused on the authentic development of self (Perrot, 2015; Chu et al., 2013). When education and learning environments develop students as strong positive people who have confidence in their ability no matter what the circumstances, when education builds quality nurturing relationships with staff, educators and the school, and when environments are inclusive so that they reflect and legitimise Pacific culture, connections and values, the result is academic achievement. If educators apply the law of 'indirect effort' by steering their focus on the development of the person through authentic cultural learning environments and the building of quality relationships with students, achievement will follow. Indirect effort refers to the process of involving people and emotional experiences in ways that are presented as an indirect influence. They come to us as a result of doing something else. In the point of developing a strong learning and teaching relationship between educator and student, there are indirect benefits for the student which facilitates their cultures, social identities and overall wellbeing.

\section{Valuing personal and academic connections beyond the textbook}

Maxwell (2007) states that “... people don't care how much you know until they know how much you care" (p. 116). Evidence suggests that when educators primarily focused on the care of Pacific students, facilitated through the development of authentic reciprocal relationships, the by-product was increased as Pacific academic achievement in tertiary study (Southwick et al., 2017; Chu et al., 2013). Students' reflections revealed that their success had more to do with the quality relationships they developed with their tutors and/or lecturers than the quality or quantity of content they received (Southwick et al., 2017; Chu et al., 2013). The realisation of equitable academic achievement for Pacific as Pacific requires academic staff to shape-shift their philosophy of teaching to be primarily about relationship building rather than content delivery. Conceptually, the relationship developed has to be seen as the vehicle which knowledge, learning, and content is funnelled through. But without a strong relationship this learning can be a barrier. 
Chu et al. (2013) identified that Pacific students across multiple institutions felt that achievement as students came about through relationships described as respectful and nurturing. The word nurturing can be explained as: To care for and protect (someone or something) while they are growing. This care and protection is evidenced as educators who go outside of their job description for Pacific students. The eagerness to put in extra one-on-one time for them, enveloped in high expectations and standards for students. Care from educators' unyielding beliefs that students can be successful with subtle coaching and mentoring of them to pursue higher level qualifications and helping them to set goals. Caring educators put in the work to ensure their teaching strategies and design was student-centred and met the needs and multiple literacies of students. Further caring staff were described as flexible, passionate and made an effort to connect with students communities and families, helping students to edge walk the multiple worlds they exist in. An example of edge walking is when an individual negotiates the multiple identities that they have. As a Tahitian and Chinese woman, I am constantly working between my cultures on a daily basis. Educators who understood or also took time to understand their Pacific students' worlds made students feel proud and strong about their multiple identities and their culture. Educators who revealed to students how to play the game of academia and to reflect critically on their success as students was a form of social justice to an education system that seemed structured in way to prevent their success (Southwick et al., 2017; Chu et al., 2013, Marshall et al., 2008). This level of care from educators ultimately protected students, and for many it enabled them for the first time to feel safe, cared for, liberated, secure, and strong as Pacific people in education.

\section{Discovering heart-warming methods of connection}

When educators put the person at the centre, the person becomes self-determined for achievement and not the other way around. Educators who put achievement over personal development are in for an arduous task if they want success for their Pacific students. Person-centred approaches to learning develop Pacific students who are eager to achieve in the long-term. They embody a strong sense of self, reflected in a strong identity as a Pacific person. They develop strong character and espouse leadership. These students are prepared for more than just education but continued positive development across the lifespan. When Pacific students are strong, they embrace their own story; when they embody self-awareness, then their learning and achievement are almost predictable. What is also rewarding is seeing the shift that happens within students when they finally feel successful (Perrot, 2015).

Success for my students was more than a grade. Covid-19 had undeniably cast university lecturing into a vacuum of tension. As I was standing in the lecture room of the Easterfield block at the university campus in the week before the first nation-wide lock down was announced, I recall feeling somewhat anxious and wary of the situation ahead. It was a surreal feeling looking at my class. Usually I am the one with the answers and plan for teaching - but it was such a space of uncertainty. As I stood there in the room I could feel myself shape-shifting between mother, lecturer and through to confused citizen. I was uncertain of what Covid-19 was presenting to us. As a third-year university class, the students were all used to coming to a lecture room to learn, to debate and to engage with one another. Technology was not the primary tool for our ways of teaching and learning and it was used minimally to communicate readings, administration processes, lecture presentations and submit assignments. Another major factor in the consideration of our 
course was the primary learning objective of working together in solving cultural challenges in education and society. As the lecturer, I needed to make sure that this class was going to be fully supported and be educated as to the purpose of the course even if the university campus was to close its campuses.

In the past decade, there has been a growing collection of educational research on Pacific learners with a greater emphasis on understanding the theoretical concepts of what works for Pacific learners as they go about their educational journeys. However, this research has been centred on the practice of the face-to face method of teaching and learning. With the Covid-19 pandemic hitting the world, universities in Aotearoa were faced with immense challenges of remote learning for students. At Te Herenga Waka I Victoria University of Wellington, my course called Multiethnic Education became a virtual safe space for learners and learning. As educators we anticipated the challenges of remote learning for our students and knew that much of our class were diverse as a student population. Diverse learners meant that there were diverse needs in relation to home situations, access to technology, economic challenges and wellbeing needs.

\section{Connecting for growth and wellbeing}

In the three weeks of face-to-face classes I made sure that I made meaningful connections with my class. Tutor and good friend, Dr Sean Fernandez was also involved in building the warmth required for our relationships in the class. His warm personality and nonjudgemental style of connecting with people made him an approachable tutor. I made sure I greeted all students, making eye contact, making enquiries into how they were doing or coping with their studies and daily life. Sean and I wanted them to know that we cared about them in a genuine and authentic way. My lecturing style is focused on a Talanoa approach and in the years of the Talanoa, I have set up a comfortable and inviting atmosphere for my students to feel like they can contribute to the lecture topic. Together we build the narrative around the topic area. Usually, I would talk to several points to probe student insights and experiences and this method allows for an entry point for them to be honest and share their experiences and perspectives. I outwardly tell my class that I am not the expert of all the knowledge, and I welcome their views. While students can learn from one another, I am also gaining their trust in an authentic and caring teaching and learning relationship. We respect one another. This becomes the foundation for trust in a way that students feel comfortable to talk, ask questions and have a certainty that our class is one where they do not have to be concerned about strict deadlines or being wrong when they speak out.

When the New Zealand Government announced a Level 4 lockdown, which meant that people were to stay at home to stop the spread of the Covid-19 virus, it felt like that as a class we had done some relationship building and preparation to learn online. The student representative of the class had already set up a Facebook page which was easily accessible by 90 percent of the students on their mobile phones. The clunky technological style of the university online teaching platform had restricted student accessibility as not every student had a laptop or Wi-Fi access at their places of residence. The sudden lockdown resulted in students moving back to their family homes and moving back to other countries. I decided to use Facebook for communicating notices such as assignment and lecture information at the beginning of a new week. One example of a message was: 
Talofa Class, I hope you are well and looking after your wairua/spirit and wellbeing. I know we have had a massive trimester and we have been dislodged with our learning. But please keep going - as year 3 students, you have the tools to be able to do this. In our Zoom class on Monday - we talked about the culture shift our country and world is going through. It is the fall of the old world and we are experiencing a huge paradigm shift. This is why we are having the journal as the third assignment. You are experiencing a culture shift and this is historic! Document it and engage with it on a creative level if you can. There are no limits as long as Sean and I can access it. Tap into your ancestral strengths! Kia kaha.

Sean and I would write up an encouraging message like this one to let the class know that we were thinking about them and that we were available for them, to help them as much as possible. Encouragement had to be expressed to the students. During the first few weeks of the lockdown, we wanted our class to feel like they had authentic connections with us. Our EDUC 322 Facebook page became an essential tool and space for teaching, learning and connections. Students expressed:

"I have honestly been so grateful for how you have all been so good to us this tri, especially during Covid-19. Thank you so much!"

"I am thankful for all of the support and help you have provided me/us for trimester 1 considering how Covid-19 hit us in so many levels. It was a struggle but also a challenge we went on to strive and persevere through trimester one!"

"You guys are the best!"

I spent many hours after my family had gone to bed to record my lectures so that these were ready and uploaded at least a week before our Zoom class meetings. This was a request from the students, so that they could have the extra time to get online to listen to the lecture. For some students there were up to eight users in a family home or flat dwelling which meant that the internet connections were slow or burnt out. I had to teach myself how to insert my recordings of my lectures into YouTube videos. It was important to make the lectures accessible and this format of YouTube videos became the primary method of lecture delivery. Students could view videos in their own time and then we would meet at the Zoom lecture room several days later. The purpose of describing this process is to show that as a lecturer I cared for my students and wanted to provide the best learning experience during challenging times.

As much as I missed the face-to-face contact with my students, we were still striving to remain as a connected village of learners. Much of my previous research (Chu et al., 2013) had pointed to the concept of a learning village which incorporates supportive spaces and necessary services for Pacific learners. As a warm alternative, the learning village positions relationships at the core of Pacific learning and teaching. The learning village is the cultivation of critical consciousness in a lecture space even in an online space, with a commitment to deepening learners' capacities with heartfelt connections.

Another relationship of significance formed in times of challenge is the strong bonds developed between students. In traditional university classes with large numbers of students, it is somewhat challenging for students to form close bonds with another. But there are methods of ensuring that students feel safe in connected in an online 
environment. With the pressure of the Covid-19 pandemic, it was essential that we (as teachers) communicated our aroha/love for our students. Each day I would post a message on our Facebook page to let them know I was thinking about them and if they needed anything to support them, we would help them out. The students later expressed to us that it was these messages that connected them as a class and to us as teachers. They felt like our course was a safe space. We also posted interesting articles, media clips and documentaries that were related to our course content. By doing this we developed a class culture. Marshall et al. (2008) in their study of best practice for Pacific students in Private Training Establishments (PTE) found that students attributed a lot of their longevity and sustainability to stick with their course and ultimately succeed to the familial relationships they developed with other students. Students got a massive benefit from being able to share expertise and ideas with fellow students, and draw strength from the cultural connections they have as fellow Pacific (Chu et al., 2013). Southwick et al. (2017) discussed how students were able to draw from the "whole group" and support each other because their programme was designed only for Pacific. Students were encouraged by tutors to look after each other which seemed different compared to the competitive messages they previously received as students in education. In our course, one of our core values through the lockdown was to look out for one another through messaging, emails and on social media. This helped to strengthen a unique bond of learning together online.

The learning village looks at the importance of the contextual and institutional factors identified from the literature that enhanced positive outcomes for Pacific students. Overall these factors enable students to feel safe and be Pacific learners in education. A learning village is essential in creating relationships that truly value Pacific students for all that they bring with their home life, peer groups, community, church context and much more. To develop a personal connection online can be viewed as challenging for any educator. However, it is possible to ensure that a learning village can be carried through to online learning, as long as the relationships are upheld in teaching and learning.

\section{Summary}

The importance of relationships for Pacific students in education is unquestionable and undeniable. If you want Pacific students to succeed in tertiary study, staff have to foster quality intentional relationships with students. Students have to feel cared for and protected by the people that are educating and supporting them. Staff as well as institutions have to foster learning environments that are collaborative and enable aiga (family) like feeling to cultivate between students. Relationship building cannot be an optional extra for educators, it has to be part of their core function. With the Covid-19 pandemic we found opportunity to connect as educators and learners in spaces beyond the lecture room and beyond the textbook. The spirit of learning did not leave us. Challenges are meant to be overcome and shape-shifting as an educator is a necessity. 


\section{References}

Chu, C., Abella, I., \& Paurini, S. (2013). Educational practices that benefit Pacific learners in tertiary education. Ako Aotearoa. https://ako.ac.nz/assests/Knowledge-centre/NPF10-001A-Pasifika-Learners-and-Success-in-Tertiary-Education/RESEARCH-REPORTEducational-Practices-that-Benefit-Pacific-Learners-in-Tertiary-Education.pdf

Marshall, J., Baldwin, K., \& Peach, R. (2008). Te rau awhina: The guiding leaf: Good practice examples of Māori and Pasifika private training establishments. New Zealand Qualifications Authority.

Maxwell, D. (2007). Improving and Learning from Practice. Journal of Pharmacy Practice and Research, 37(1), 38-41. https://doi.org/10.1002/j.2055-2335.2007.tb00656.x

Perrot, A. R. D. (2015). Overcoming Challenges: Pacific students' experiences of being resilient through tertiary education. (Unpublished master's thesis). Victoria University of Wellington.

Southwick, M., Scott, W., Mitaera, J., Nimarota, T., \& Falepau, L. (2017). Articulating a pedagogy of success for Pacific students in tertiary education.

https://ako.ac.nz/assets/Knowledge-centre/NPF-14-004-Articulating-and-implementinga-pedagogy-of-success-for-Pacific-students-in-tertiary-

education/5d213fbf60/RESEARCH-REPORT-Articulating-a-Pedagogy-of-Success-for-

Pacific-Students-in-Tertiary-Education.pdf

Cherie Chu-Fuluifaga is a Pacific academic-activist who strives to work for changes for Pacific people. As a result, her university courses are centred on educating learners to be community leaders in Aotearoa. Cherie has taught and researched in Pacific education for over 20 years in Aotearoa and in the Pacific region.

Email: cherie.chu-fuluifaga@vuw.ac.nz

ORCiD: https://orcid.org/0000-0002-1490-8103 